\title{
Insight Into Behavior Displayed During Deception
}

\author{
ALDERT VRIJ \\ University of Portsmouth \\ GÜN R. SEMIN \\ Vrije Universiteit \\ RAY BULL \\ University of Portsmouth
}

\begin{abstract}
Previous research suggests that liars are not aware that they tend to decrease their movements during deception. Moreover, it is unclear how liars will behave if someone informs them about their behavioral rigidity during deception, and to what extent several processes (tension, attempted behavioral control, and cognitive effort) are associated with deception. In the present experiment, subjects were interviewed twice. During one interview, they told the truth, and during the other interview, they lied. In the information-present condition, before both interviews, subjects were told that deception is usually associated with a decrease in movements. In the information-absent condition, no information was given. The results revealed that whereas subjects believed that they increased their movements during deception, a decrease in movements, in fact, occurred. Provision of information about deceptive behavior had no effect. The results also showed that a decrease in movements was associated with attempted control and cognitive load processes, and occurred independently from the tension experienced by deceivers.
\end{abstract}

I $\mathrm{n}$ deception research, a distinction is usually made between actual and perceived indicators of deception (DePaulo, Stone, \& Lassiter, 1985; Zuckerman, DePaulo, \& Rosenthal, 1981). Actual indicators of deception consist of nonverbal behaviors that have been found to be associated with deception. Perceived indicators of deception are nonverbal behaviors that observers associate with deception, regardless of whether such behavior is manifested during deception. Several meta-analyses have provided evidence that deceiving others is correlated with more speech disturbances (both "ahs" and "non-ahs"), a higher pitched voice, and a shorter response length (DePaulo et al., 1985; Vrij,

Aldert Vrij is a senior lecturer of social and legal psychology at the University of Portsmouth, United Kingdom. Gün R. Semin is a professor of social psychology at the Vrije Universiteit, Amsterdam, The Netherlands. Ray Bull is a professor of psychology at the University of Portsmouth, United Kingdom. This study was supported by a grant from the Recherche Advies Commissie (RAC) of the Dutch Ministry of Justice.

Human Communication Research, Vol. 22 No. 4, June 1996 544-562

(C) 1996 International Communication Association 
1991; Zuckerman, DePaulo, et al., 1981; Zuckerman \& Driver, 1985). More recent studies have found that deception, especially when liars are highly motivated, is associated with a decrease in hand, foot, and leg movements (Davis \& Hadiks, 1995; DePaulo, 1992; Ekman, 1989; Ekman, O'Sullivan, Friesen, \& Scherer, 1991; Höfer, Köhnken, Hanewinkel, \& Bruhn, 1992; Vrij, 1993b, 1995).

Meta-analyses and recent studies concerning perceived indicators of deception (De Paulo, 1992; DePaulo et al., 1985; Ekman, 1989; Vrij, 1991, 1993a, 1993b; Vrij \& Semin, in press; Vrij \& Winkel, 1992, 1994; Zuckerman, DePaulo, et al., 1981) provide empirical evidence that observers associate deception with a variety of nonverbal behaviors, such as many speech disturbances (more "ahs" and "non-ahs"), a higher-pitched voice, a slower speech rate, a longer latency period, more gaze aversion, less smiling, and more movements (self-touches; movements of the trunk; shifting positions; and hand, arm, leg, and foot movements). ${ }^{1}$

These reviews of perceived and actual indicators of deception reveal a striking pattern regarding body movements. People believe that deception is associated with an increase in movements; in contrast, actual deception is associated with a decrease in movements.

A possible explanation of why observers associate deception with an increase in movements is that they assume that liars are nervous and that they will behave nervously when lying (Knapp, Hart, \& Dennis, 1974; Köhnken, 1989; Kraut \& Poe, 1980). Valid indicators of nervous behavior include random movements and self-manipulations (Burgoon, Kelley, Newton, \& Keely-Dyreson, 1989; Burgoon \& LePoire, 1992; Davis \& Hadiks, 1995; DeTurck \& Miller, 1985). ${ }^{2}$

Two theoretical frameworks, namely, the attempted control framework and the cognitive load framework, are often used to explain the actual relationship between movements and deception. The attempted control framework assumes that deceivers are tense. However, unlike observers' beliefs, this framework does not predict nervous behavior during deception. According to this framework, liars try to control their body language to avoid giving off possible nonverbal cues to deception and to make a credible (reliable) impression (DePaulo, 1988, 1992; DePaulo \& Kirkendol, 1989; Ekman, 1989; Köhnken, 1990). Paradoxically, deceivers' very attempts to control their behavior serve as cues to deception. The controlled behavior will appear planned, rehearsed, and lacking in spontaneity. Liars, for instance, believe that movements will make them appear suspicious. Therefore, they will move very deliberately and tend to avoid those movements that are not strictly essential. This results in an unusual degree of rigidity and inhibition. In agreement with this explanation, Vrij (1995) found that deception is actually associated with a decrease in subtle, 
nonfunctional movements, such as hand and finger movements and foot and leg movements.

The cognitive load framework (Burgoon et al., 1989; Ekman \& Friesen, 1972; Goldman-Eisler, 1968; Köhnken, 1989) emphasizes that deception is a cognitively complex task. It assumes that it is more cognitively difficult to fabricate a plausible and convincing lie consistent with everything the observer knows or might find out than to tell the truth. There is evidence to suggest that people engaged in cognitively complex tasks make less hand and arm movements; the cognitive load results in a neglect of body language, reducing overall animation (Ekman \& Friesen, 1972). Although both the attempted control and the cognitive load framework predict a decrease in movements during deception, the explanations are different. According to the attempted control framework, a decrease in movements is caused by an overcontrol of movements. The cognitive load framework, however, does not contend that liars try to control their behavior; rather, the decrease in movements is held to be the result of a neglect of body language.

We would like to point out here that in the usual deception studies, the attempted control and cognitive load framework are not tested empirically. The studies usually focus only on nonverbal behavioral differences between liars and truth tellers; both frameworks are then introduced afterward to explain the observed differences, and no information is given about which framework is the better explanation. Therefore, it is unclear to what extent deceivers do experience the attempted control or cognitive load during deception, whether and how these processes influence deceptive behavior, and which framework is the more appropriate for explaining deceptive behavior. The present experiment investigates these issues.

In daily life, people are involved in both deceiving others (telling "white lies," for instance) as well as detecting deceit. This makes the difference in actual and perceived indicators concerning body movement interesting; why do people tend to decrease their own subtle movements during deception and yet believe that others tend to increase their movements during deception? A probable explanation for this contradiction is that deceivers are not aware that they tend to decrease their subtle movements when lying; perhaps they think that they increase their movements during deception. ${ }^{3}$ If deceivers are not aware of their movements during deception, how will they behave if someone informs them about the actual movements-deception relationship? It seems reasonable to suggest that such knowledgeable deceivers will try to "correct" themselves (to show natural behavior) by less overcontrolling their subtle movements. We think, however, that some overcontrol will remain, due to cognitive load.

In the present experiment, subjects were interviewed twice. Each subject had to tell the truth during one interview and had to lie during the 
other. All interviews were videotaped. After the interviews, subjects were asked for their views about the amount of movements they had made during both interviews. Furthermore, they were asked to indicate how nervous they were during both interviews; to what extent they had tried to control their movements; and to what extent they believed that deception was a cognitively complex task. In the information-present condition, prior to both interviews, subjects were told that deception is usually associated with a decrease in subtle movements. In the informationabsent condition, no such information was given.

In the present experiment, five hypotheses were tested:

H1: Deception will be associated with fewer subtle, nonfunctional movements, such as hand and finger movements and foot and leg movements than will truth telling.

$\mathrm{H} 2$ : Subjects in the information-present condition will make more subtle movements when lying than will subjects in the information-absent condition; no difference in movements is expected between the two information conditions in the truth-telling interviews.

H3: Subjects in the information-present condition will think they have made more subtle movements when lying than lying subjects in the informationabsent condition will think they have made; no difference is expected between the two information conditions in the truth-telling interview.

H4: Subjects will experience more tension, attempted control, and cognitive load during deception than when telling the truth (i.e., they will feel more tense during deception than when telling the truth, they will try to control their movements more strongly during deception than when telling the truth, and they will perceive deception as a more cognitively complex task than telling the truth); due to the provided information, the experienced attempted control and cognitive load during deception will be more visible in the information-present condition than in the information-absent condition.

H5: Decreases in subtle movements will be associated with attempted control and cognitive load and will occur independently from nervousness.

The experiment was conducted at two locations, namely, Amsterdam (The Netherlands) and Portsmouth (United Kingdom). This comparative aspect was introduced to find out whether subjects belonging to different cultures will behave differently during deception and/or will have different beliefs about their own behavior during deception. We did not formulate a hypothesis concerning this cross-cultural comparison, because we did not expect differences among the two cultural contexts. Previous research (Köhnken, 1990; Vrij \& Winkel, 1991) revealed no differences between Western cultures in behavior during deception nor in beliefs about behaviors during deception. 


\section{METHOD}

\section{Subjects}

A total of 51 British and 40 Dutch subjects (university students) participated in the study; $45 \%$ were male, $55 \%$ were female. ${ }^{4}$ The average age was 23 years $(S D=5$ years).

\section{Procedure}

The experiment was conducted at the Vrije Universiteit in Amsterdam and the University of Portsmouth in the United Kingdom. Subjects were asked to participate in a study investigating their ability to deceive. Subjects were paid 10 guilders or 3 pounds for their participation.

The setting was a simulated police interview similar to the ones used in previous studies (Vrij, 1995; Vrij \& Winkel, 1991). Subjects were given the following instructions:

We are doing an experiment to investigate people's ability to deceive. In a minute, you will be interviewed twice by a uniformed police officer about the possession of a small set of headphones. You will actually have the set of headphones in your possession during one interview, while during the other interview you will not have the set of headphones in your possession. Both times you have to deny the possession of the set of headphones.

To motivate the subjects, it was emphasized that making a credible impression is an important quality for a flourishing career, because people who are skilled at impression management are found to be intelligent (DePaulo, Kirkendol, Tang, \& O'Brien, 1988; DePaulo, Lanier, \& Davis, 1983; Ekman \& Friesen, 1972; Ekman et al., 1991; Kraut \& Poe, 1980). DePaulo et al. (1988) found that subjects who received this information beforehand were more motivated than subjects who did not receive this information.

The order of lying versus telling the truth was counterbalanced. A total of 46 subjects received the set of headphones before the first interview, with the request to hide them carefully; the other 45 subjects received the set of headphones just before the second interview. This group had seen the set of headphones prior to the first interview. After the instructions, the experimenter brought the subjects to the interview room. The interviewer (a uniformed police detective) ${ }^{5}$ asked the subject to take a seat and started the first interview. All interviews were standardized: The following six questions were asked:

1. "Do you have the set of headphones in your possession?"

2. "Are you telling the truth?"

3. "Tell me exactly what you have in your possession." 
4. "You forgot to mention the set of headphones, didn't you?"

5. "Are you telling me that you don't have the headphones in your possession?"

6. "Are you absolutely sure that you are telling me the truth?"

After the first interview, the subject left the interview room for a short period of time either to return the set of headphones to the experimenter (if the subject was in the possession of the set of headphones during the first interview) or to receive the set of headphones (if the subject was not in the possession of the set of headphones during the first interview). Next, the subject reentered the interview room for the second interview. The second interview was identical to the first one. Both interviews were videotaped. On the videotapes, the subjects' whole bodies are visible. The average length of the honest interviews was 26 seconds ( $S D=4$ seconds); the average length of the deceptive interviews was 27 seconds $(S D=5$ seconds). Following the second interview, subjects were asked to fill out a questionnaire concerning, among other things, their judgments about their own behavior during both interviews.

\section{Independent Variables}

The independent variables are (a) the type of interview (lying vs. telling the truth), (b) the order in which the honest and deceptive interviews were carried out, that is, lying/telling the truth or telling the truth/lying, (c) origin of the subjects (The Netherlands vs. the United Kingdom), and (d) information about actual indicators of deception (present or absent). In the information-present condition, subjects $(n=43)$ received the following oral information prior to the interviews:

Research has shown that deception is associated with a decrease in subtle movements, such as hand and finger movements and foot and leg movements. ${ }^{6}$ One explanation is that liars believe that movements will give their lies away. Therefore, they will move very deliberately and tend to avoid those movements which are not strictly essential. This results in an unusual degree of rigidity and inhibition. Another explanation is that deceiving is a cognitively (mentally) difficult task (people have to think harder). This cognitive load results in a neglect of body language.

The experimenter checked whether the subjects understood this information by asking them to recall the information. All subjects successfully recalled the information. ${ }^{7}$ In the information-absent condition $(n=48$ subjects), no such information was given.

\section{Dependent Variables}

The dependent variables are the movements displayed by the subjects, subjects' impressions about their own behavior, and their experience of 
emotional, attempted control and cognitive load processes during both interviews.

\section{Actual Behavior}

The movements displayed by the subjects was scored in detail by two independent coders, using the videotapes. Scoring was conducted by using the Observation Nonverbal Behavior (ONB) scoring system developed by Vrij $(1991,1995)$ and Vrij and Winkel (1991), which is partly derived from scoring systems used by Duncan and Fiske (1977), Ickes and Turner (1983), Koomen, Van de Bovenkamp, and Forma (1983), Kraut and Poe (1980), and Mehrabian (1972). ONB is a scoring system specially developed for practitioners in applied settings (such as police interviews). The system is easy to use and aims to register all the (clearly) visible movements.

The following six movements were scored:

1. Frequency of head movements, that is, the frequency of head nods and head shakes. A head shake or head nod often consists of a series of brief head nods and head shakes. These series were scored as one head nod or head shake ( 2 coders, $r=.64, p<.001$ ).

2. Frequency of shifting positions, that is, movements made to change the sitting position. Shifting positions are usually accompanied with several small trunk movements; these series of trunk movements were scored as one shifting position. Shifting positions are sometimes accompanied with limb movements; these movements were scored separately, namely, as foot and leg movements and as gestures ( 2 coders, $r=.77, p<.001$ ).

3. Frequency of foot and leg movements, that is, movements of feet and legs. Every single movement of feet and legs was scored: Simultaneous movements of feet and legs were scored as one movement; continuing movements were scored every two seconds ( 2 coders, $r=.94, p<.001$ ).

4. Frequency of gestures, that is, functional hand and arm movements, such as hand and arm movements designed to modify and/or supplement what is being said verbally and hand and arm movements to accompany a shifting position. Every single movement was scored. Gestures always consist of simultaneous movements of the hand and arm; these simultaneous movements were scored as one movement $(2$ coders, $r=.89, p<.001)$.

5. Frequency of self-manipulations, that is, scratching the head, wrists, and so forth. Every single self-manipulation was scored. Rubbing one's hands together and fidgeting are not coded as a self-manipulation but as a hand/ finger movement, the reason for this being that coders in previous studies (Vrij, 1991, 1995) found it difficult to distinguish between "hand/finger self-manipulations" and "hand/finger movements" ( 2 coders, $r=.98, p<$ $.001)$.

6. Frequency of hand/finger movements (also referred to as hand movements). A hand movement is a movement of a hand without the arm being moved; 
TABLE 1

Results of the Factor Analysis

\begin{tabular}{lccc}
\hline \hline & & Factors \\
\cline { 2 - 4 } & $\begin{array}{l}\text { Nervous } \\
\text { Behavior }\end{array}$ & $\begin{array}{c}\text { Subtle } \\
\text { Movements }\end{array}$ & $\begin{array}{c}\text { Supportive } \\
\text { Behavior }\end{array}$ \\
\hline Eigenvalue & 1.73 & 1.28 & 1.05 \\
Percentage variance & 29 & 21 & 18 \\
Self-manipulations & .84 & -.14 & .12 \\
Shifting position & .77 & .26 & .01 \\
Hand and finger movements & -.07 & .81 & .12 \\
Foot and leg movements & .17 & .81 & -.04 \\
Gestures & .36 & .02 & .66 \\
Head movements & -.10 & .06 & .86 \\
\hline
\end{tabular}

finger movements are movements of fingers without hands or arms being moved. Every single hand/finger movement was scored; simultaneous movements of more fingers were scored as one movement; continuing movements, rubbing one's hands together, and fidgeting were scored every 2 seconds ( 2 coders, $r=.97, p<.001$ ).

The behavioral scores are based on the average scores of the two coders. The duration and frequency of all categories of nonverbal behavior reported below have been corrected for length of the interview: The behaviors have been calculated on a per minute basis. ${ }^{8}$

A principal-components factor analysis using varimax rotation was performed to gain insight into the behavioral dimensions lying at the basis of the six movements. Three factors explained $68 \%$ of the variance. The results of the factor analysis are provided in Table 1.

The first factor included self-manipulations and shifting positions and explained $29 \%$ of the variance. This factor will be referred to as Nervous Behavior; previous research has revealed that these movements are indicators of increased arousal (Burgoon et al., 1989; Burgoon \& LePoire, 1992; DeTurck \& Miller, 1985). The second factor consisted of hand/finger movements and foot and leg movements and explained $21 \%$ of the variance. This factor will be referred to as Subtle Movements (Vrij, 1995). Our previous research has found that these movements are valid indicators of deception (Vrij, 1995). The third factor included gestures and head movements and explained $18 \%$ of the variance. This factor will be referred to as Supportive Behavior; previous research has shown that gestures and these movements are designed to modify and/or supplement what is being said verbally (Vrij, Akehurst, Van Dalen, Van Wijngaarden, \& Foppes, 1996). 


\section{Impressions About Own Behavior}

Following the second interview, subjects were requested to complete a questionnaire in which they were asked to give their impressions about their own behavior in both interviews. Questions were asked about each of the six behaviors listed in Table 1. Subjects had to give their impressions (on 7-point rating scales) about their behavior during lying and truth telling separately. To clarify the behavioral categories (and the distinctions between the categories), an explanation of each of the six behaviors was given. An example is: ${ }^{9}$

Making head movements (head nods and head shakes) while LYING:

$\begin{array}{llllllllll}\text { never } & 1 & 2 & 3 & 4 & 5 & 6 & 7 & \text { very often }\end{array}$

Making head movements while TELLING THE TRUTH:

$\begin{array}{lllllllll}\text { never } & 1 & 2 & 3 & 4 & 5 & 6 & 7 & \text { very often }\end{array}$

\section{Underlying Processes}

Five questions were asked to investigate possible underlying processes while lying. Answers could be given on 7-point scales, ranging from (1) certainly not to (7) certainly. One question related to the attempted control process: "While lying you attempted to control your behavior." Three questions related to tension: "While lying you were aroused physically (for instance, an increased heart rate)"; "While lying you felt guilty (for instance, guilty about engaging in deception)"; and "While lying you were anxious (anxiety about being caught)." One question related to the cognitive load: "Lying needed a lot of mental effort (for instance, to prevent contradictions and/or logical inconsistencies)." Data regarding the three questions relating to tension (physical arousal, guilt, and anxiety) were then collapsed into one tension scale (Cronbach's alpha $=.76) .{ }^{10}$

Similar questions were asked regarding the possible underlying processes during truth telling (the questions were obtained by substituting "telling the truth" for "lying"). Data for the three questions relating to tension (physical arousal, guilt, and anxiety) were again collapsed into one tension scale (Cronbach's alpha $=.73$ ).

\section{RESULTS}

To test the hypotheses that deception will be associated with fewer subtle, nonfunctional movements, such as hand and finger movements and foot and leg movements than will truth telling (H1); that subjects in the information-present condition will make more movements when 
TABLE 2

Means, $\boldsymbol{F}$ Values, and $\eta^{2}$ Concerning

Actual Behavior and Impressions of One's

Own Behavior as a Function of Type of Interview

\begin{tabular}{|c|c|c|c|c|}
\hline \multirow[b]{3}{*}{ Dependent Variables } & \multicolumn{2}{|c|}{ Type of Interview } & \multirow[b]{3}{*}{$\mathrm{F}(1,83)$} & \multirow[b]{3}{*}{$\eta^{2}$} \\
\hline & Lying & $\begin{array}{l}\text { Telling } \\
\text { the Truth }\end{array}$ & & \\
\hline & M & $\mathbf{M}$ & & \\
\hline \multicolumn{5}{|l|}{ Actual behavior } \\
\hline Subtle movements & 14.35 & 18.52 & $5.34^{*}$ & .06 \\
\hline Nervous behavior & .82 & .92 & .31 & .00 \\
\hline Supportive behavior & 22.38 & 21.45 & 1.43 & .01 \\
\hline \multicolumn{5}{|l|}{ Impression about behavior } \\
\hline Impression about subtle movements & 2.75 & 2.48 & $15.85^{* *}$ & .16 \\
\hline Impression about nervous behavior & 2.59 & 2.46 & $4.48^{*}$ & .05 \\
\hline Impression about supportive behavior & 3.58 & 3.41 & $5.85^{*}$ & .07 \\
\hline
\end{tabular}

NOTE: The means concerning actual behaviors represent the frequency of occurrence on a per minute basis. The means concerning impressions about behaviors are scored on 7-point rating scales, ranging from (1) never to (7) very often.

${ }^{*} p<.05 .{ }^{* *} p<.01$.

lying than will lying subjects in the information-absent condition (whereas no differences in movements were expected between the two information conditions in the honest interview $)(\mathrm{H} 2)$; and that subjects in the information-present condition will think they have made more movements when lying than subjects in the information-absent condition will think they have made (whereas no differences were expected between the two information conditions in the honest interview) (H3), a MANOVA was conducted using a 2 (Type of Interview: lying or telling the truth) $\times 2$ (Information: present or absent) $\times 2$ (Order: lying/telling the truth or telling the truth/lying) $\times 2$ (Origin: Dutch or British) factorial design. The first factor was a within-subjects factor; the other three factors were between-subjects factors. The dependent variables were the movements made by the subjects and their impressions about these movements. These dependent variables are provided in Table 2. At a multivariate level, the analysis revealed two significant main effects-namely, for Information, $F(6,78)=2.99, p<.05, \eta^{2}=.19$, and Type of Interview, $F(6,78)=4.06, p<$ $.001, \eta^{2}=.24-$ but no significant interaction effects. Univariate effects and mean scores concerning both main effects are provided in Table 2 and Table 3.

Table 2 reveals that deception was associated with fewer subtle movements than was telling the truth. $\mathrm{H} 1$ was thus supported. Moreover, Table 2 shows that subjects thought they had displayed more movements during deception than when telling the truth. Table 3 reveals that subjects 
TABLE 3

Means, $F$ Values, and $\eta^{2}$ Concerning

Actual Behavior and Impressions of One's Own Behavior as a Function of Information

\begin{tabular}{lrrrrr}
\hline \hline & \multicolumn{2}{c}{ Information } & & \\
\cline { 2 - 3 } & No & Yes & & \\
\cline { 2 - 3 } Dependent Variables & $\mathrm{M}$ & $\mathrm{M}$ & $\mathrm{F}(1,83)$ & $\eta^{2}$ \\
\hline Actual behavior & & & & \\
$\quad$ Subtle movements & 16.63 & 16.22 & .00 & .00 \\
$\quad$ Nervous behavior & 1.03 & .69 & .42 & .01 \\
$\quad$ Supportive behavior & 19.72 & 24.37 & $7.85^{* *}$ & .09 \\
Impression about behavior & & & & .08 \\
$\quad$ Impression about subtle movements & 2.29 & 2.98 & $7.32^{* *}$ & .07 \\
Impression about nervous behavior & 2.25 & 2.84 & $6.41^{*}$ & .02 \\
$\quad$ Impression about supportive behavior & 3.33 & 3.69 & 1.94 & \\
\hline
\end{tabular}

NOTE: The means concerning actual behaviors represent the frequency of occurrence on a per minute basis. The means concerning impressions about behaviors are scored on 7-point rating scales, ranging from (1) never to (7) very often.

${ }^{*} p<.05 .{ }^{* *} p<.01$.

made more movements in the information-present condition than in the information-absent condition (they especially displayed more supportive behavior, that is, gestures and head movements). Finally, Table 3 shows that subjects in the information-present condition thought they had made more movements than subjects in the information-absent condition thought they had made. $\mathrm{H} 2$ predicted a Type of Interview $\times$ Information interaction effect with regard to subtle movements. This effect was not significant, $F(1,83)=1.88$, ns. Contrast analyses showed that the information neither had an impact on the number of subtle movements made in the deception interviews, $F(1,89)=.34, n s$, nor had an impact on the number of subtle movements made in the truth-telling interviews, $F(1,89)=.37$, $n s$. $\mathrm{H} 2$ was thus not supported.

$\mathrm{H} 3$ predicted a Type of Interview $\times$ Information interaction effect with regard to impressions about subtle movements. This effect was marginally significant, $F(1,83)=3.41, p=.068$, two-tailed, $\eta^{2}=.04$. Contrast analyses showed, in line with $\mathrm{H} 3$, that subjects in the information-present condition thought they had made more subtle movements when lying than subjects in the information-absent condition thought they had made $\left(M=3.17\right.$ vs. $\left.M=2.37, F[1,89]=9.83, p<.01, \eta^{2}=.10\right)$. However, contrary to the prediction in $\mathrm{H} 3$, subjects in the information-present condition also thought they had made more subtle movements when telling the truth than subjects in the information-absent condition thought they had made $\left(M=2.79\right.$ vs. $\left.M=2.21, F[1,89]=7.56, p<.01, \eta^{2}=.08\right)$. Hence, $\mathrm{H} 3$ was partly supported. 
To test $\mathrm{H} 4$ (subjects will experience more tension, attempted control, and cognitive load during deception than when telling the truth; due to the information provided, the experienced attempted control and cognitive load during deception will be more visible in the information-present condition than in the information-absent condition), a MANOVA was conducted, again using a 2 (Type of Interview: lying or telling the truth) $\times$ 2 (Information: yes or no) $\times 2$ (Order: lying/telling the truth or telling the truth/lying) $\times 2$ (Origin: Dutch or British) factorial design. Dependent variables were the three possible underlying processes. The multivariate analysis yielded two significant main effects-namely, for Origin, $F(3$, $81)=3.48, p<.05, \eta^{2}=.11$, and Type of Interview, $F(3,81)=32.21, p<.01$, $\eta^{2}=.54$. No significant interaction effects emerged. Univariate tests with regard to the Origin factor showed a significant effect for cognitive load, $F(1,83)=8.24, p<.01, \eta^{2}=.09$. The mean scores revealed that both interviews required more cognitive load for British subjects than for Dutch subjects $(M=3.48$ vs. $M=2.63)$. Univariate tests regarding the Type of Interview factor revealed significant effects for attempted control, $F(1,83)=$ $40.42, p<.01, \eta^{2}=.33$; tension, $F(1,83)=85.09, p<.01, \eta^{2}=.51$; and cognitive load, $F(1,83)=36.07, p<.01, \eta^{2}=.30$. The mean scores showed that subjects did experience more tension during deception $(M=4.24)$ than when telling the truth $(M=2.76)$, tried harder to control their behavior during deception $(M=5.37)$ than when telling the truth $(M=4.24)$, and found lying mentally more complex $(M=3.74)$ than telling the truth $(M=2.47)$. $\mathrm{H} 4$ predicted Type of Interview $\times$ Information interaction effects regarding attempted control and cognitive load. None of these interaction effects were significant, however, $F(1,83)=.02$, ns, and $F(1,83)=.32$, ns, respectively. Moreover, additional contrast analyses revealed that subjects in the information-present condition tried as hard to control their behavior during deception as subjects in the information-absent condition, $F(1,89)=.08, n s$, and that subjects in the information-present condition found lying as mentally complex during deception as did subjects in the information-absent condition, $F(1,89)=.90, n s$. $\mathrm{H} 4$ was therefore partly supported.

To test H5 (the decrease in subtle movements will be associated with attempted control and cognitive load and will occur independently from nervousness), one ANOVA and three ANCOVAs were performed, again using a 2 (Type of Interview: lying or telling the truth) $\times 2$ (Information: present or absent) $\times 2$ (Order: lying/telling the truth or telling the truth/ lying) $\times 2$ (Origin: Dutch or British) factorial design. The dependent variable was subtle movements. In the three ANCOVAs, the variables cognitive load, attempted control, and tension were the covariates. $\mathrm{H} 5$ implied that the decrease in subtle movements during deception (main effect previously presented in Table 2) will disappear with attempted control or cognitive load as covariates, and will remain with tension as a 
covariate. The main analysis showed a significant effect, $F(1,89)=5.08$, $p<.05, \eta^{2}=.05$. The analysis with tension as a covariate also showed a significant effect, $F(1,89)=6.77, p<.05, \eta^{2}=.07$. Neither the analysis with cognitive load as a covariate $\left(F[1,89]=2.54, n s, \eta^{2}=.02\right)$ nor the analysis with attempted control as a covariate $\left(F[1,89]=1.62, n s, \eta^{2}=.02\right)$ yielded significant results. These results thus support $\mathrm{H} 5$ and indicate that a decrease in movements is associated with attempted control and cognitive load processes, and occurs independently from the tension experienced by deceivers. To confirm the latter part of this conclusion, two different scores were correlated, namely, the self-reported tension while lying, minus telling the truth, and subtle movements while lying, minus telling the truth. This correlation was not significant, $r(91)=.15, n s$. Finally, an analysis of covariance was conducted in which attempted control and cognitive load were introduced as covariates simultaneously. The analysis resulted in an even less powerful $F$ value $\left(F[1,88]=.50, n s, \eta^{2}=.01\right)$.

\section{DISCUSSION}

In the present experiment, actual behavior during deception, beliefs regarding one's own behavior during deception, and processes underlying deceptive behavior were examined. The experiment revealed that deception was associated with a decrease in subtle movements (hand/ finger movements and foot and leg movements), indicating that rigidity occurs during deception.

Reviews concerning perceived indicators of deception (see introduction) revealed that observers on the one hand associate an increase instead of a decrease in movements with deception, and on the other hand associate more nonverbal cues with deception than in fact reveal deception. The major difference between the present experiment and previous studies concerning perceived indicators of deception is that in our experiment, the observers reporting their perceptions were the actual deceivers, the ones who had just participated in the truths and lies, and whose behavior was the basis of the computation of the actual cues to deceit; in other studies, the subjects are merely observers who are judging others' behavior. The results of our experiment showed that deceivers did not know how their own deceptive behavior appears. They believed that they increased their movements during deception, whereas, in fact, a decrease in movements occurred. Moreover, they believed that there were differences in all three behaviors (subtle movements, nervous behavior, and supportive behavior), whereas, in reality, only a difference in subtle movements occurred. These findings are similar to those of previous studies concerning perceived indicators of deception. This implies that during deception, not only observers but deceivers themselves (a) expect 
that more cues reveal deception than in fact is true, and (b) do not know exactly which behavioral pattern reveals deception. Hence our findings give a possible explanation as to why observers are not knowledgeable about indicators of deception: When judging someone's credibility, observers are looking at cues they think they themselves reveal during deception; unfortunately, they are not sufficiently aware of their own behavior during deception.

It was explained to one group of subjects (the information-present condition) that deceivers tend to decrease their movements, in particular subtle movements, during deception. It was expected that subjects in this information-present condition would adapt their strategy by showing more subtle movements when lying, to minimize the difference in subtle movements between lying and truth telling. In other words, an information by type of interview interaction effect was expected, whereby subjects in the information-present condition would show more subtle movements when lying than would subjects in the information-absent condition; however, no differences in movements between the two information conditions were expected in the honest interviews. However, this interaction effect was not found. Instead, a decrease in subtle movements during deception occurred (main effect), indicating that a decrease occurred even when the subjects were told that this exposes deceptive intent. Moreover, subjects in the information-present condition displayed more supportive behaviors (gestures and head movements) than did subjects in the information-absent condition (main effect), indicating that they increased their supportive behaviors instead of their subtle movements as a result of the information given. Why did the expected increase in subtle movements not occur, and why, in the information-present condition, did an increase in supportive behavior occur instead? Perhaps subtle movements are beyond the control of subjects, possibly because of the cognitive load of lying and/or physical inability to control these movements efficiently. While trying to increase these subtle movements, subjects instead increased their other visible movements. Such an explanation would provide further evidence for the "beyond control" notion, although further research is needed to test this notion. This finding may have important practical implications as well. It suggests that knowledge about actual cues of deception does not change deceivers' deceptive behavior. One point bears mentioning in this context. We did not give our subjects the opportunity to practice their control of subtle movements. Perhaps, after a training session, they would be more successful in influencing their subtle movements than they were in the present experiment. Further research is needed to test this issue.

In the research literature, two theoretical frameworks (processes) to account for a decrease in movements during deception are usually mentioned, that is, cognitive load and attempted control. However, to our 
knowledge, whether subjects experience these processes during deception and whether these processes are actually associated with deception has never been investigated. These issues were addressed in the present experiment by asking the subjects whether they experienced these processes during deception, and by determining whether the decrease in subtle movements was associated with experiences of attempted control and cognitive load. The findings indicate that subjects did experience both processes during deception, that is, they had tried to control their behavior during deception and they indicated that deception was a cognitively more complex task then telling the truth. Moreover, results showed that the decrease in subtle movements was in fact associated with the experience of attempted control and cognitive load.

The information provided had an effect on subjects' behavior and on subjects' impressions about their own behavior but did not influence the experience of the attempted control and cognitive load processes. A possible explanation is that deceivers are usually aware of control and cognitive load processes during deception; as a result, the information was not new and did not influence these processes. However, deceivers do not know how these processes affect their behavior; as a result, the information was new in this respect and therefore influenced behavior and impressions about behavior.

In other words, the findings give some direct evidence concerning the role of attempted control and cognitive load in deceiving; although a caution has to be given. The two processes were investigated via a self-report (using one item) and the data were correlational and did not allow for causal inferences. It seems worthwhile to conduct further experimental studies manipulating the level of cognitive load and attempted control to obtain stronger evidence (by means of causal data) concerning these issues. Cognitive load could be manipulated by introducing "easy" and "difficult" lies (e.g., easy lies could be obtained by telling subjects prior to the deception task exactly what they have to say during the deception task). Attempted control could be manipulated by giving subjects correct or incorrect information about the role of attempted control during deception (examples of incorrect information could include telling the subjects that a lack of control reveals deceptive intent, or that an overcontrol of clearly visible movements gives one away).

The literature reveals that observers tend to neglect these attempted control and cognitive load processes when they try to detect deception. They especially associate deception with tension and, therefore, they are looking for cues indicating nervous behavior to determine whether someone is deceitful or telling the truth (DePaulo et al., 1985; Vrij, 1991, 1993a; Zuckerman, DePaulo, et al., 1981; Zuckerman \& Driver, 1985). Our results confirmed observers' assumptions that deception is associated with tension; that is, subjects did experience more tension during deception than 
when telling the truth. However, our outcomes suggest that it is incorrect to believe that nervousness affects deceivers' behavior. Both the analysis of covariance and the correlation showed that behavioral differences between deception and telling the truth did occur independently from the tension experienced by the subjects. These data were correlational, however. Thus, in future studies, it seems worthwhile to manipulate the level of tension that allows causal inferences (it could then be useful to measure tension via self-reports and physiological measures instead of via selfreports only; see Burgoon et al., 1989, for the relevance of using different measures in investigating tension). Unfortunately, in all deception studies conducted so far (including our study), the stakes are usually pretty low (at least compared to real-life events such as police interviews, interviews with customs officers, and so forth), and subjects are unlikely to experience much tension. How do people behave in high-stakes situations, and to what extent is their behavior associated with tension, attempted control, and cognitive load? Further research is needed to investigate this issue. Anticipating such a study, it is likely that the outcomes will strengthen the pattern found in previous studies. For instance, in high-stakes situations, liars are more tense and more motivated to get away with their lies, and, as a meta-analysis (Zuckerman \& Driver, 1985) revealed, highly motivated liars make fewer movements than do less motivated liars, probably due to the fact that highly motivated liars try harder to control their behavior and consequently move less and display more behavioral rigidity.

The study was conducted at two different locations (Amsterdam, The Netherlands, and Portsmouth, United Kingdom). For this reason, location was included as a factor in the analyses. This factor revealed a significant main effect concerning cognitive load. The interviews required more cognitive load for British subjects than for Dutch subjects. We can only speculate about an explanation for this finding. The two locations differ from each other in several respects. For instance, Amsterdam is a metropolitan city. It might be the case that metropolitan cities attract more students from outside than smaller cities-students who are perhaps more talkative, more arrogant, and less shy, and therefore find lying less taxing. More important, despite the possible differences between the two samples, we did not find any differences between Dutch and British subjects regarding deceptive behavior, giving some evidence that particular deceptive behavior (a decrease in subtle movements) is a phenomenon that occurs in different cultures.

\section{NOTES}

1. Perceived indicators of deception are sometimes determined by asking subjects directly what they think that they (or others in general) do differently when lying compared 
to when telling the truth (e.g., Gordon, Baxter, Rozelle, \& Druckman, 1987; Vrij \& Semin, in press; Zuckerman, Koestner, \& Driver, 1981) and are sometimes based on subjects judgments of deceptiveness. In the latter method, subjects typically watch a video recording of truth telling and lying, and indicate when each occurs. These judgments are then correlated with the actual cues that were or were not present in each clip (Kraut, 1978; Kraut \& Poe, 1980; Vrij, 1993a; Vrij \& Winkel, 1992, 1994). Both of these methods result in similar outcomes, at least as far as movements are concerned.

2. In addition, various nonmovement behaviors, namely longer pauses, longer response latencies, more speech errors, and briefer answers to questions, are indicators of nervousness (Burgoon et al., 1989; DeTurck \& Miller, 1985).

3. This assumption does not mean that we favor the cognitive load framework more than the attempted control framework. It is possible that deceivers, although they attempt to control their movements, still think that they make more movements than do truth tellers.

4. As far as we know, prior research has never found gender effects. Therefore, gender was not included as a factor in the analysis. To justify this decision, additional analyses were conducted with gender included as the fifth factor. These analyses showed similar results to the analyses described in the Results section.

5. We used a British and a Dutch detective. By way of instructions and exercises, their performances were standardized.

6. Research outcomes suggest that liars in certain conditions, namely when they are highly motivated, tend to decrease other movements as well, in particular head movements and shifting positions (for a review, see Zuckerman \& Driver, 1985). To keep comprehensive the information provided to the subjects, we decided to withhold from the subjects this extra detailed and slightly complicated information.

7. We did not include manipulation checks in the questionnaire. Therefore, we cannot check whether the subjects did really understand the information provided and/or whether they still remembered this information after the interviews.

8. Aggregating behaviors across the entire interaction might be considered a potential limitation, because differences in nonverbal behavior during the course of the interaction cannot be analyzed. To gain insight into these differences requires a segmentation analysis.

9. A possible limitation of this study is that we did not check whether the subjects understood what should and should not count under the various categories of behaviors.

10. In deception literature, it is supposed that deception is associated with feelings of anxiety and guilt, resulting in physical arousal (DePaulo et al., 1985; Köhnken, 1989; Zuckerman, DePaulo, et al., 1981).

\section{REFERENCES}

Burgoon, J. K., Kelley, D. L., Newton, D. A., \& Keely-Dyreson, M. P. (1989). The nature of arousal and nonverbal indices. Human Communication Research, 16, 217-255.

Burgoon, J. K., \& LePoire, B. A. (1992). A reply from the heart: Who are Sparks and Greene and why are they saying all these horrible things? Human Communication Research, 18, 472-483.

Davis, M., \& Hadiks, D. (1995). Demeanor and credibility. Semiotica, 106, 5-54.

DePaulo, B. M. (1988). Nonverbal aspects of deception. Journal of Nonverbal Behavior, 12, 153-162.

DePaulo, B. M. (1992). Nonverbal behavior and self-presentation. Psychological Bulletin, 111, 233-243.

DePaulo, B. M., \& Kirkendol, S. E. (1989). The motivational impairment effect in the communication of deception. In J. C. Yuille (Ed.), Credibility assessment (pp. 51-70). Dordrecht, The Netherlands: Kluwer. 
DePaulo, B. M., Kirkendol, S. E., Tang, J., \& O'Brien, T. P. (1988). The motivational impairment effect in the communication of deception: Replications and extensions. Journal of Nonverbal Behavior, 12, 177-203.

DePaulo, B. M., Lanier, K., \& Davis, T. (1983). Detecting deceit of the motivated liar. Journal of Personality and Social Psychology, 45, 1096-1103.

DePaulo, B. M., Stone, J. L., \& Lassiter, G. D. (1985). Deceiving and detecting deceit. In B. R. Schenkler (Ed.), The self and social life (pp. 323-370). New York: McGraw-Hill.

DeTurck, M. A., \& Miller, G. R. (1985). Deception and arousal: Isolating the behavioral correlates of deception. Human Communication Research, 12, 181-201.

Duncan, S., \& Fiske, D. W. (1977). Face to face interaction: Research methods and theory. Hillsdale, NJ: Lawrence Erlbaum.

Ekman, P. (1989). Why lies fall and what behaviors betray a lie. In J. C. Yuille (Ed.), Credibility assessment (pp. 71-82). Dordrecht, The Netherlands: Kluwer.

Ekman, P., \& Friesen, W. V. (1972). Hand movements. Joumal of Communication, 22, 353-374.

Ekman, P., O'Sullivan, M., Friesen, W. V., \& Scherer, K. R. (1991). Face, voice, and body in detecting deceit. Journal of Nonverbal Behavior, 15, 125-136.

Goldman-Eisler, F. (1968). Psycholinguistics: Experiments in spontaneous speech. New York: Doubleday.

Gordon, R. A., Baxter, J. C., Rozelle, R. M., \& Druckman, D. (1987). Expectations of honest, evasive and deceptive nonverbal behavior. Journal of Social Psychology, 127, 231-233.

Höfer, E., Köhnken, G., Hanewinkel, R., \& Bruhn, Ch. (1992). Diagnostik und attribution von glaubwürdigkeit [Assessment and attribution of credibility] (Final report to the Deutsche Forschungsgemeinschaft, KO 882/4-2). Kiel, Germany: University of Kiel.

Ickes, W., \& Turner, M. (1983). On the social advantages of having older, opposite-sex sibling: Birth order influences in mixed-sex dyads. Journal of Personality and Social Psychology, 45, 210-222.

Knapp, M. L., Hart, R. P., \& Dennis, H. S. (1974). An exploration of deception as a communication construct. Human Communication Research, 1, 15-29.

Köhnken, G. (1989). Behavioral correlates of statement credibility: Theories, paradigms and results. In H. Wegener, F. Lösel, \& J. Haisch (Eds.), Criminal behavior and the justice system: Psychological perspectives (pp. 271-289). New York: Springer-Verlag.

Köhnken, G. (1990). Glaubwürdigkeit: Untersuchungen zu einem psychologischen konstrukt [Credibility: A psychological analysis]. Munich, Germany: Psychologie Verlags Union.

Koomen, W., Van de Bovenkamp, J., \& Forma, H. (1983). De relatie tussen non-verbale gedragskenmerken en waarneming van gespannenheid door "actor" en "observer" [Actors' and observers' perceptions of nonverbal indicators of tension]. Nederlands Tijdschrift voor de Psychologie, 38, 433-444.

Kraut, R. E. (1978). Verbal and nonverbal cues in the perception of lying. Journal of Personality and Social Psychology, 36, 380-391.

Kraut, R. E., \& Poe, D. (1980). On the line: The deception judgments of customs inspectors and laymen. Journal of Personality and Social Psychology, 36, 380-391.

Mehrabian, A. (1972). Nonverbal communication. Chicago: Aldine-Atherton.

Vrij, A. (1991). Misverstanden tussen politie en allochtonen: sociaal-psychologische aspecten van verdacht zijn [Misunderstandings between the police and ethnic minorities: Social psychological aspects of being a suspect]. Amsterdam: VU Uitgeverij.

Vrij, A. (1993a). Credibility judgments of detectives: The impact of nonverbal behavior, social skills and physical characteristics on impression formation. Journal of Social Psychology, $133,601-611$.

Vrij, A. (1993b). Objectieve en subjectieve indicatoren van misleiding [Objective and subjective indicators of deception]. The Hague, The Netherlands: Ministerie van Justitie, Recherche Advies Commissie. 
Vrij, A. (1995). Behavioral correlates of deception in a simulated police interview. Journal of Psychology, 129, 15-29.

Vrij, A., Akehurst, L., Van Dalen, D., Van Wijngaarden, J. J., \& Foppes, J. H. (1996). Nonverbaal gedrag en misleiding in een gesimuleerd politie-verhoor [Nonverbal behavior and deception in a simulated police interview]. Tijdschrift voor de Politie, 58, 11-14.

Vrij, A., \& Semin, G. R. (in press). Lie experts' beliefs about indicators of deception. Journal of Nonverbal Behavior.

Vrij, A., \& Winkel, F. W. (1991). Cultural patterns in Dutch and Surinam nonverbal behavior: An analysis of simulated police interviews. Journal of Nonverbal Behavior, 15, 169-185.

Vrij, A., \& Winkel, F. W. (1992). Cross-cultural police-citizen interactions: The influence of race, beliefs and nonverbal communication on impression formation. Journal of Applied Social Psychology, 22, 1546-1559.

Vrij, A., \& Winkel, F. W. (1994). Perceptual distortions in cross-cultural interrogations: The impact of skin color, accent, speech style and spoken fluency on impression formation. Journal of Cross-Cultural Psychology, 25, 284-296.

Zuckerman, M., DePaulo, B. M., \& Rosenthal, R. (1981). Verbal and nonverbal communication of deception. In L. Berkowitz (Ed.), Advances in experimental social psychology (Vol. 14, pp. 1-59). New York: Academic Press.

Zuckerman, M., \& Driver, R. E. (1985). Telling lies: Verbal and nonverbal correlates of deception. In A. W. Siegman \& S. Feldstein (Eds.), Multichannel integrations of nonverbal behavior (pp. 129-147). Hillsdale NJ: Lawrence Erlbaum.

Zuckerman, M., Koestner, R., \& Driver, R. (1981). Beliefs about cues associated with deception. Journal of Nonverbal Behavior, 6, 105-114. 